\title{
Towards understanding the myometrial physiome: approaches for the construction of a virtual physiological uterus
} Michael John Taggart*1, Andrew Blanks², Sanjay Kharche3 ${ }^{3}$, Arun Holden ${ }^{4}$, Bin Wang 5 and Henggui Zhang ${ }^{3}$

\begin{abstract}
Address: ${ }^{1}$ Maternal and Fetal Health Research Centre, University of Manchester, St Mary's Hospital, Hathersage Road, Manchester, M13 0JH, UK, ${ }^{2}$ Clinical Sciences Research Centre, Warwick Medical School, Coventry, UK, ${ }^{3}$ School of Physics, University of Manchester, Manchester, M13 9PL, UK, ${ }^{4}$ Institute of Membrane \& Systems Biology, University of Leeds, Leeds, UK and ${ }^{5}$ School of Engineering and Physical Sciences, University of Aberdeen, Aberdeen, UK

Email: Michael John Taggart* - michael.j.taggart@manchester.ac.uk; Andrew Blanks - Andrew.Blanks@warwick.ac.uk; Sanjay Kharche - sanjay.kharche@manchester.ac.uk; Arun Holden - arun@cbiol.leeds.ac.uk; Bin Wang - bin.wang@abdn.ac.uk; Henggui Zhang - H.Zhang-3@manchester.ac.uk

* Corresponding author
\end{abstract}

from Special Non-Invasive Advances in Fetal and Neonatal Evaluation Network of Excellence, First and Second European Workshops on Preterm Labour Tarragona, Spain. 21-22 September 2006 and 22 June 2005

Published: I June 2007

BMC Pregnancy and Childbirth 2007, 7(SuppI I):S3 doi:10.1 I86/147I-2393-7-SI-S3

This article is available from: http://www.biomedcentral.com/I47I-2393/7/SI/S3

(c) 2007 Taggart et al; licensee BioMed Central Ltd.

This is an open access article distributed under the terms of the Creative Commons Attribution License (http://creativecommons.org/licenses/by/2.0), which permits unrestricted use, distribution, and reproduction in any medium, provided the original work is properly cited.

\begin{abstract}
Premature labour (PTL) is the single most significant factor contributing to neonatal morbidity in Europe with enormous attendant healthcare and social costs. Consequently, it remains a major challenge to alleviate the cause and impact of this condition. Our ability to improve the diagnosis and treatment of women most at risk of PTL is, however, actually hampered by an incomplete understanding of the ways in which the functions of the uterine myocyte are integrated to effect an appropriate biological response at the multicellular whole organ system. The level of organization required to co-ordinate labouring uterine contractile effort in time and space can be considered immense. There is a multitude of what might be considered mini-systems involved, each with their own regulatory feedback cycles, yet they each, in turn, will influence the behaviour of a related system. These include, but are not exclusive to, gestational-dependent regulation of transcription, translation, post-translational modifications, intracellular signaling dynamics, cell morphology, intercellular communication and tissue level morphology.

We propose that in order to comprehend how these mini-systems integrate to facilitate uterine contraction during labour (preterm or term) we must, in concert with biological experimentation, construct detailed mathematical descriptions of our findings. This serves three purposes: firstly, providing a quantitative description of series of complex observations; secondly, proferring a database platform that informs further testable experimentation; thirdly, advancing towards the establishment of a virtual physiological uterus and in silico clinical diagnosis and treatment of PTL.
\end{abstract}




\section{Background}

'The challenge to interpret this vast volume of data at the genomic and proteomic level in terms of function at higher levels is exactly what modern physiology is about. ' [1].

The development of improved methods of diagnosis and treatment of preterm labour (PTL) is the major task facing obstetric research in this new millennium. PTL accounts for $6-8 \%$ of all births across Europe ( $6 \%$ in the UK) [2]. Of even greater significance is that $75 \%$ of neonatal deaths, and most neonatal intensive care admissions, arise from preterm babies born before 32 weeks of pregnancy [3]. Oft-overlooked is the realisation that the impact of PTL is long-lasting; prematurely born children face a high risk of disability and life-long ill health. In a recent follow-up study of 308 UK children born prematurely ( $<26$ weeks), the rates of severe, moderate and mild disability at 6 years of age were 22\%, 24\% and 34\% respectively [4]. The short- and long-term economic consequences of preterm birth also place a considerable burden on society as a whole [5]. It is, therefore, a considerable cause of concern that the prevention of PTL, or the treatment of established PTL, remains seriously inadequate; in fact, the rates of PTL have not declined in the last 20 years. It is paramount, therefore, that we advance our understanding of uterine physiology, in all its complexities, in order to improve our diagnosis and treatment of PTL.

Perhaps our greatest challenge ahead, as evoked in the quotation above, is to consider how we can assimilate the vast arrays of molecular and cellular information currently generated into a proper physiological context: biological systems are often dynamic, non-linear, nonhomogeneous and operate at various mesmerising levels of organisation and hierarchy. Still yet more complexity is introduced with the remodelling of physiological events during pregnancy and labour. Figure 1 illustrates just some of the complexities that one has to wrestle with when studying human uterine physiology whether at subcellular, single cell, multicellular, whole organ or whole organism levels. It is this consideration of integrated uterine function that is encapsulated by the term 'myometrial physiome'.

Underpinning this goal is our quest to answer the questions of (i) what are the cellular mechanisms regulating myometrial contractility? and (ii) what factors control the timing of onset of labour? Much of the research in the former field has been led by reductionist principles, if inadvertently. We have very focussed research questions that often allow us to assess the expression of a gene(s), the encoded protein(s) and, hopefully, make an assessment of its location and function in the myometrial cell. Determining the answer to these strictly defined questions

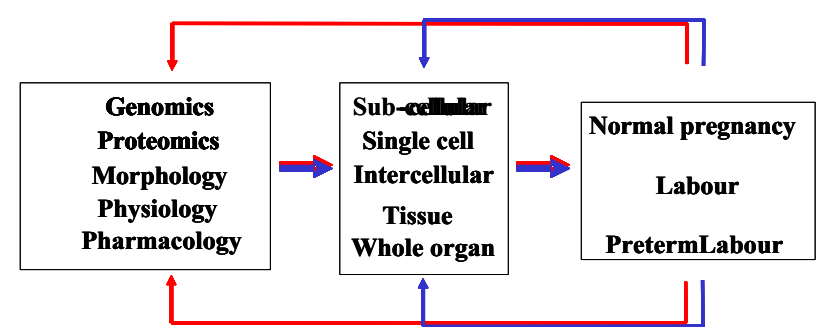

\section{Figure I}

Network domains for the myometrial physiome.

Interlinked modalities that one must consider in developing an understanding of the virtual physiological uterus.

then informs our development of further hypothesisdriven research aims. As just one example, such strategies have been employed to investigate the possible roles of proteins associated with specialised structures of the myometrial cell membrane - caveolae - in the signal processing of contractile stimuli ([6-8] and Figure 2); this, therefore, has encompassed studies of genes and encoded proteins, cell signalling dynamics, cell ultrastructure and contractile function of the myometrium. In the postgenomic age, the use of high-throughput 'omic strategies has offered alternative, but complimentary, approaches to exploring the above questions and these needn't be so deterministic in outlook [9-11]. The common link, however, is that we must take an integrative approach to interpreting any such data: for example, consider we have the question 'what are the global patterns of myometrial gene expression accompanying onset of labour?'. Collecting multiple arrays of mRNA expression data is of considerable use in answering this question yet still only tells us part of the story of how gene expression alterations contribute to uterine development and priming for parturition (term or preterm). We have to also consider how these patterns are controlled by other, epigenetic factors in utero stimuli, be they endocrine, nutritional or metabolic for example, that impact upon gene expression without a change in nucleotide sequence of the genome [12]. Thus we must consider the mechanisms behind chemical modifications of DNA (such as cytosine methylation) or histones (lysine acetylation or methylation) or miRNA binding to DNA, all of which can influence gene transcript expression. Add to this cellular/regional variations in responsiveness, as well as patient biological divergence, and the complexity of analysis of even just two modalities of Figure 1 (gene expression and labour) becomes immense.

Computational biological methods, however, offer a promising way forward in advancing our understanding of integrated uterine function and answering the above questions. Procedures for the modelling and simulation 
(i)

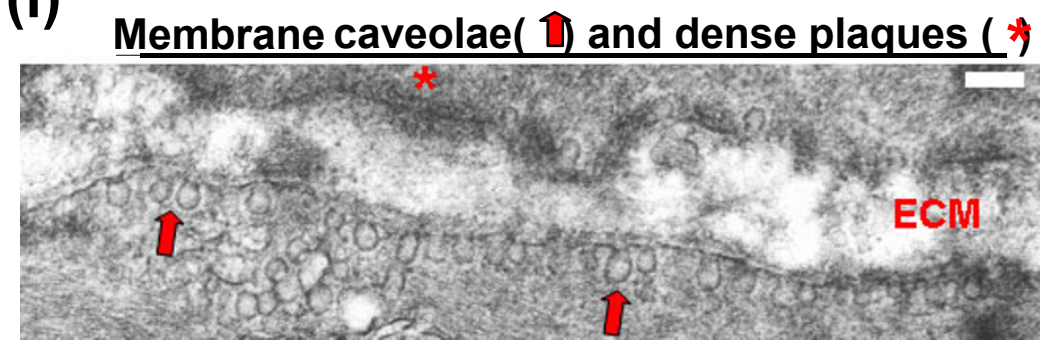

(ii)

\section{Caveolin-1 protein localisation}

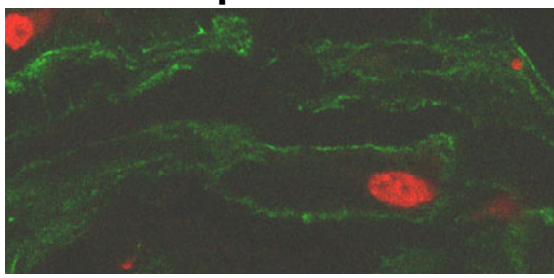

Cellular morphology

(iii)

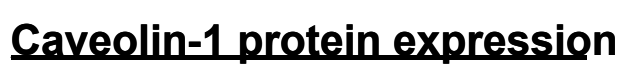

PNL
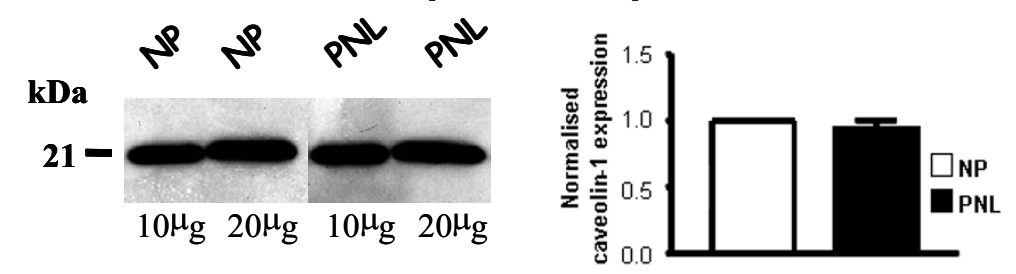

(iv)

Caveolin-1 mRNA expression
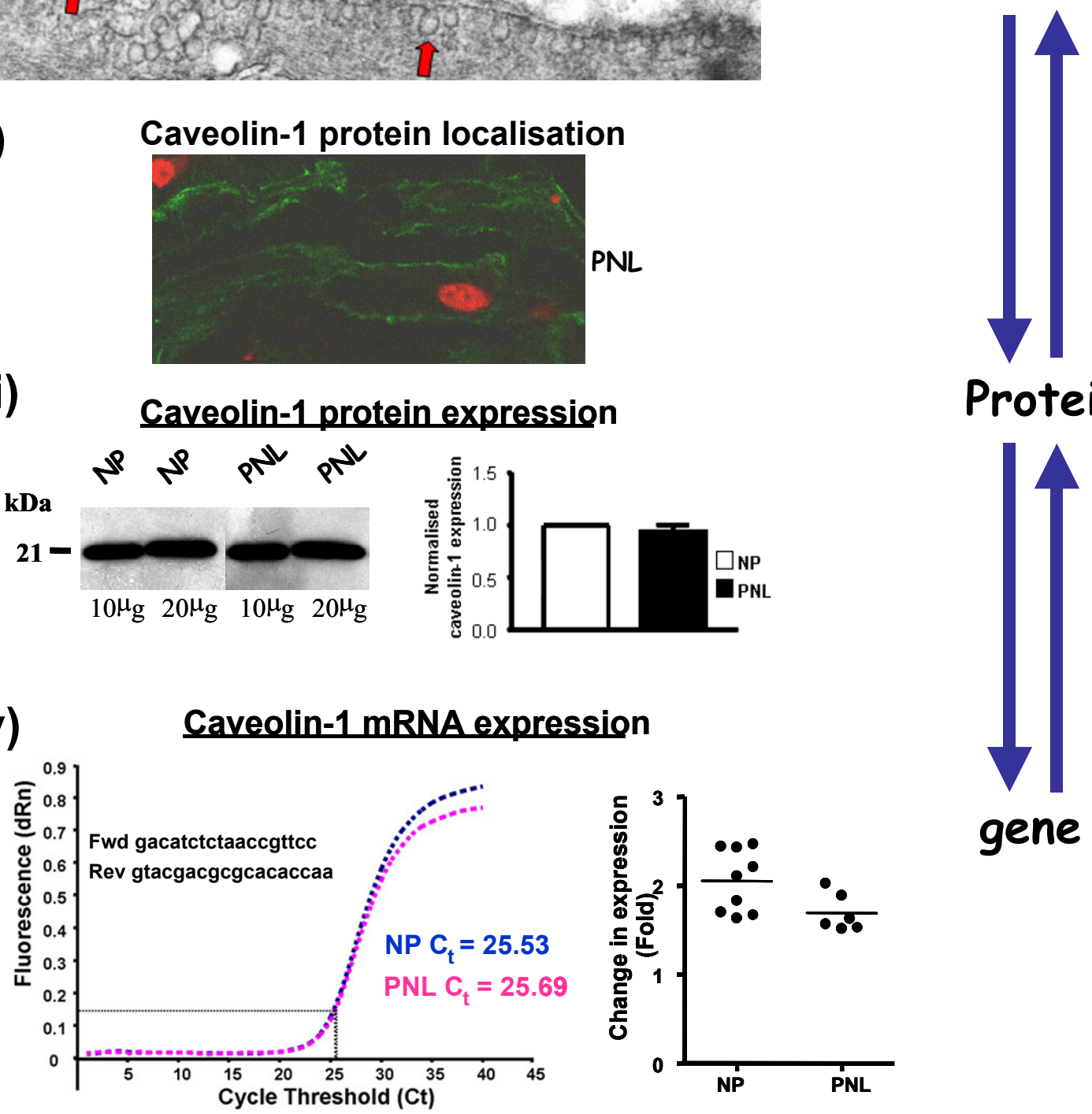

\section{Protein}

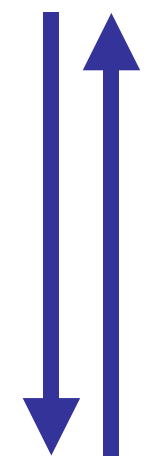

gene

Figure 2

Example of gene-protein-cellular morphology modalities for the myometrial physiome. Investigation of the role of even one gene of the uterus - caveolin-I in this case - crosses such modalities. (i) Caveolae - sarcolemmal invaginations identifiable by electron microscopy (red arrows) are thought to orchestrate uterine intracellular signalling dynamics. (ii) CaveolinI protein is an integral structural and regulatory component of caveolae. Consistent with this, caveolin-I (green) is localised by immunofluorescent confocal microscopy primarily to the plasma membrane. (iii) and (iv) Caveolin-I protein or mRNA expression is invariant between myometrium of non-pregnant (NP) and pregnant not in labour (PNL) women.

of complex mini-system networks at all levels of modality illustrated in Figure 1 are now commonplace and a number of advanced mathematical tools can be utilised to describe genetic, metabolic, protein, signalling, single cell and multicellular networks [13]. As an example, we have begun to construct mathematical models of human myo- 


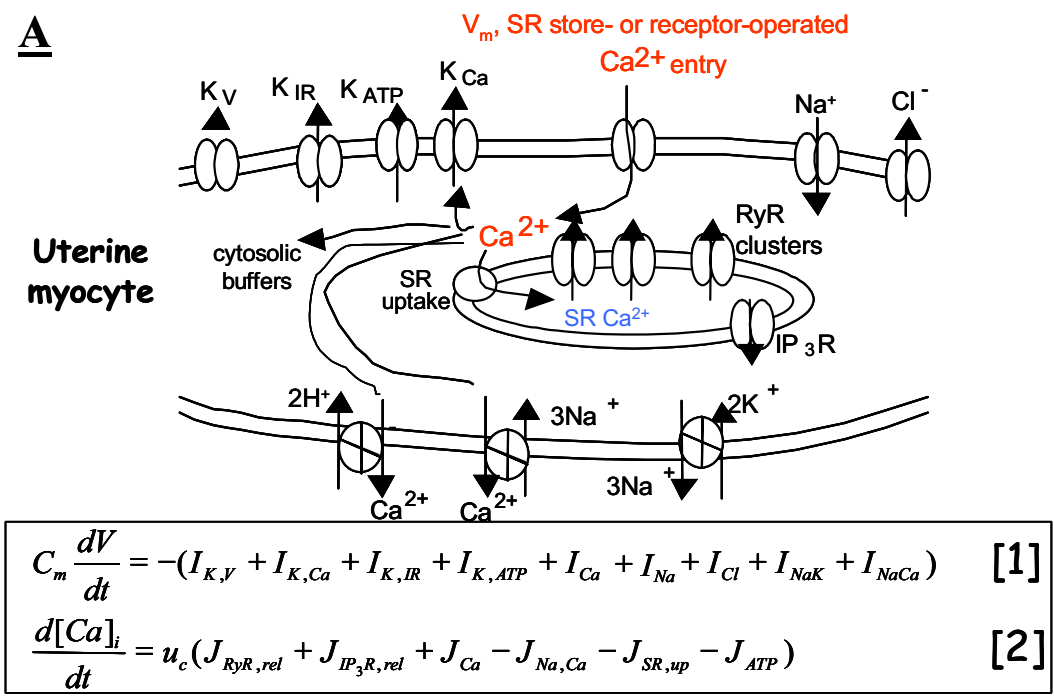

$\mathrm{mV}$

$\underline{\mathbf{B}}$

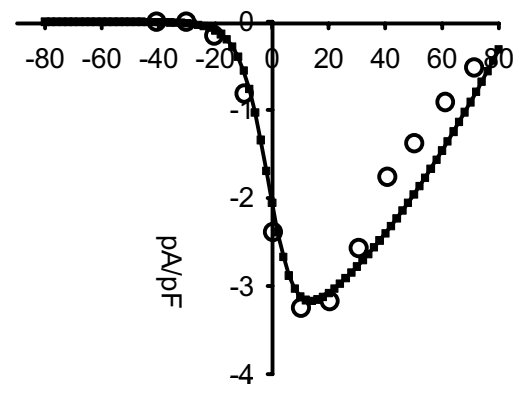

$\underline{\mathbf{C}}$

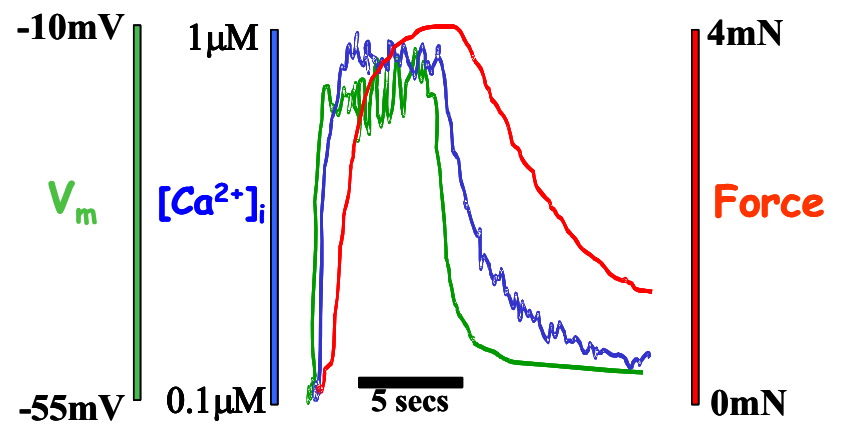

\section{Single cell ion kinetics}

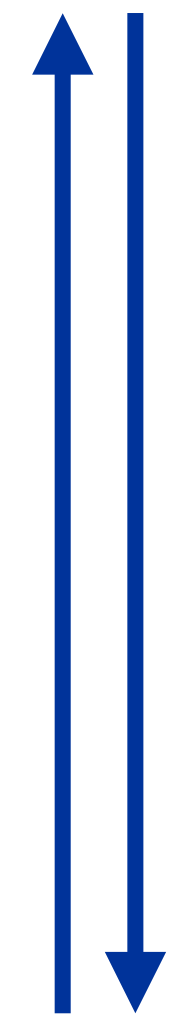

\section{Tissue-level electrophysiological coupling}

\section{Figure 3}

Example of single cell to whole tissue modalities for the myometrial physiome. (A) The net ionic current flowing across an uterine myocyte in unit time is the sum of many individual currents measurable by voltage clamp electrophysiology. The net current flow (equation [I]) and the cellular fluxes of intracellular $\mathrm{Ca}^{2+}$ (equation [2]) can be modeled by differential equations. (B) Mathematical descriptions of particular ion channel characteristics can contribute to the construction of biophysically detailed models of cell excitability. Here, the inward $\mathrm{Na}^{+}$current data of [20] (open circles) can be stringently modeled as depicted by the solid line. (C) This information at the single cell level must, in due course, be extended to provide a rigorous model to explain tissue level function such as that depicted here - periodic fluctuations in membrane potential, intracellular $\mathrm{Ca}^{2+}$ and force occurring in situ (adapted from [2I]). $\mathrm{K}_{\mathrm{IR}}, \mathrm{K}_{\mathrm{v}}, \mathrm{K}_{\mathrm{ATP}}, \mathrm{K}_{\mathrm{Ca}_{\mathrm{a}}}$ refer to inward rectifying, voltage-, ATP- or Cadependent $\mathrm{K}$ channels, respectively. $\mathrm{V}_{\mathrm{m}}$, membrane potential. $\mathrm{C}_{\mathrm{m}}$, membrane capacitance. SR, sarcoplasmic reticulum. RyR, ryanodine receptors. 
$\underline{\mathbf{A}}$

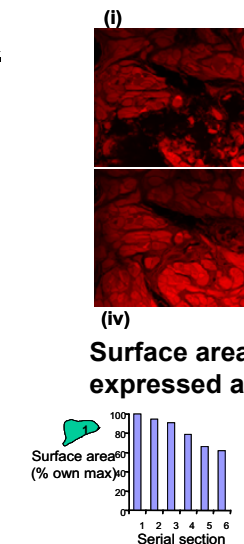

(ii) (iii)

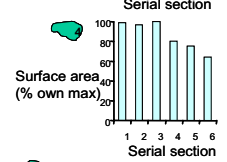

(v)

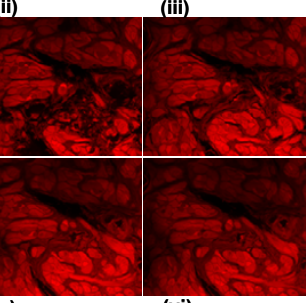

Serial confocal sections of PSR stained myometriumfrom pregnant woman at term.

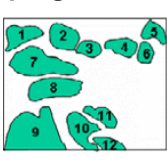

$9 \sqrt{1090}$ a \% of total SA in each serial section.
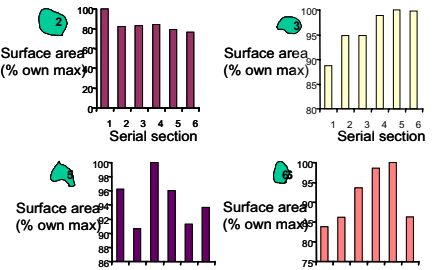

Surface are ${ }^{20}$
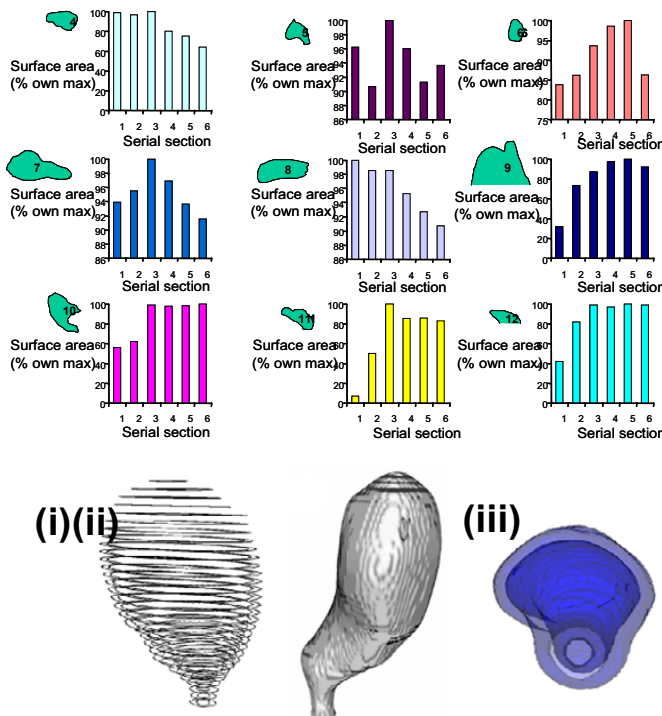

$\underline{C}$

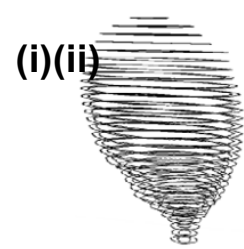

(i)(ii)

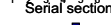

$\underline{\mathbf{B}}$

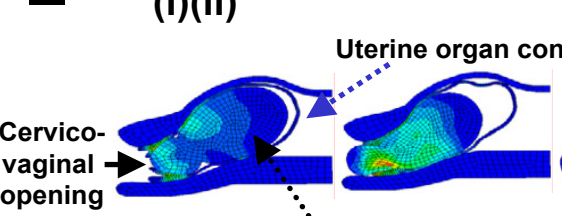

Fetalprogression through utero-vaginal canal

(iii)

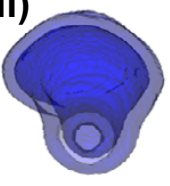

(iii)(iv)

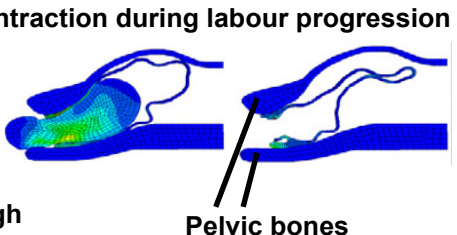

Tissue morphology

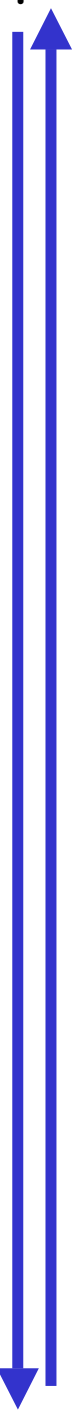

Whole organ digital reconstruction

Figure 4

Example of multicellular tissue to whole uterus modalities for the myometrial physiome. Quantitative 3-dimensional reconstruction of tissue level morphological data contributes to models of whole organ function. $\mathbf{A}$, an uterine biopsy is fixed and stained with picrosirius red and serial optical sections examined by laser confocal microscopy. The surface areas of distinct myometrial cell bundles can be quantified through the depth of the scanned tissue to monitor cellular geometry. B, digital reconstruction of late third trimester gravid human uterus from magnetic resonance imaging data sets; from left to right: (i) the 3D stacks of extracted uterine wall boundaries; (ii) surface view of the reconstructed 3D geometry (iii) semi-transparent view through the cervix. C, from left to right (i-iv), computerised simulation of uterine and fetal movements in the final stage of active labour enables consideration of whole organ physiology in concert with pelvic skeleton biomechanics. Colour-coded brightness (blue-red) reflects intensity of pressure exerted on the fetus as it passes through the birth canal. 
metrial function that integrate biophysical details from current experimentation and that in the literature [e.g. [14]]. Ion channel activation/inactivation kinetics data can be used to construct models of the electrical action potential of a single cell using sets of coupled differential equations (Figure 3). Similar approaches can be used to consider descriptions of the spatiotemporal flux of intracellular $\mathrm{Ca}^{2+}$ (Figure 3 ). In concert with further experimentation - including cell-specific transcriptomics, in vitro and in vivo high resolution imaging techniques and in vivo pressure and electromyographic recordings [15-17] mathematical approaches can then be utilized to gradually build the rigour and complexity of such models to consider cell-to-cell communication, tissue level cellular geometry and whole organ anatomy and biomechanics (Figure $4 ;[14]$ ). Eventually, this will enable simulation of 4-dimensional patterns of uterine cellular excitability and organ contraction: a virtual physiological uterus.

\section{Conclusion}

There is an overall goal underpinning our wish to combine theoretical and empirical approaches to understanding uterine physiology and pathophysiology. That is, to eventually establish a comprehensive and rigorous model of integrated gravid uterine function that enables the application of non-invasive in silico tools for predicting the physiological impact of any new treatment regimens for women at the risk of preterm labour. In other words, the creation of a virtual physiological uterus. Similar approaches have been exceptionally successful in the last 15 years at informing us of the function (and dysfunction) of isolated cardiac cells, specialised cardiac regions or the heart as a whole [18].

A final consideration concerns establishing meaningful access to the divergent datasets related to PTL for computational modelling purposes by the academic community of biologists, chemists, mathematicians and clinicians. Certainly this requires a web-based forum for the storage, and continued supplementation, of datasets in a standardized, well-defined and cross-referenced manner with open access to software tools allowing for model developments and data analysis $[11,19]$.

\section{Competing interests}

The authors declare that they have no competing interests.

\section{Authors' contributions}

MJT and HZ conceived of the study, and participated in its design and coordination and helped to draft the manuscript. $\mathrm{AB}$ participated in the design of the study and coordination and, together with MJT, performed the experiments of Figure 4A. SK performed the mathematical modelling of Figure 3B. AH participated in the design of the study and contributed Figure 4B. BW contributed to the study co-ordination and Figure 4C.

\section{Acknowledgements}

This paper was supported by funding from Action Medical Research (MJT, $A B)$, Wellcome Trust (MJT), EU Network of Excellence BioSim (AVH) and the EU SAFE Network of Excellence (LSHB-CT-2004-503243). Publication costs were supported by Ferring, Serono and Perkin Elmer. Written consent was obtained from the patient or their relative for publication of this study.

This article has been published as part of BMC Pregnancy and Childbirth Volume 7, Supplement I, 2007: Proceedings of the First and Second European Workshops on Preterm Labour of the Special Non-Invasive Advances in Fetal and Neonatal Evaluation (SAFE) Network of Excellence. The full contents of the supplement are available online at http://www.biomedcen tral.com/I47I-2393/7! issue $=$ SI.

\section{References}

I. Crampin EJ, Halstead M, Hunter P, Nielsen P, Noble D, Smith N, Tawhai M: Computational physiology and the physiome project. Exp Physiol 2004, 89:I-26.

2. Lopez Bernal A: Overview of current research in parturition. Exp Physiol 200I, 86:213-222.

3. Slattery MM, Morrison JJ: Preterm delivery. Lancet 2002, 360: $1489-1497$

4. Marlow N, Wolke D, Bracewell MA, Samara M: Neurologic and developmental disability at six years of age after extremely preterm birth. N Engl J Med 2005, 352:9-19.

5. Petrou S: The economic consequences of preterm birth during the first 10 years of life. BJOG 2005, I I 2(SuppI I): I0-15.

6. Lee Y-H, Hwang M-K, Morgan KG, Taggart MJ: Receptor-coupled contractility of uterine smooth muscle: from membrane to myofilaments. Exp Physiol 200I, 86:283-288.

7. Riley M, Baker PN, Tribe RT, Taggart MJ: Expression of Scaffolding, Signalling and Contractile-Filament Proteins in Human Myometria: Effects of Pregnancy and Labour. I Cell Mol Med 2005, 9:122-134.

8. Riley M, Wu X, Baker PN, Taggart MJ: Gestational-dependent changes in the expression of signal transduction and contractile filament-associated proteins in mouse myometrium. J Soc Gynecol Investig 2005, I 2:e33-e43.

9. Charpigny G, Leroy MJ, Breuiller-Fouche M, Tanfin Z, Mhaouty-Kodja S, Robin P, Leiber D, Cohen-Tannoudji J, Cabrol D, Barberis C, Germain G: A functional genomic study to identify differential gene expression in the preterm and term human myometrium. Biol Reprod 2003, 68:2289-2296.

10. Havelock JC, Keller P, Muleba N, Mayhew BA, Casey BM, Rainey WE, Ann Word RA: Human Myometrial Gene Expression Before and During Parturition. Biol Reprod 2005, 72:707-719.

II. Kell D: Metabolomics and systems biology. Curr Opin Microbiol 2004, 7:296-307.

12. Gluckman PD, Hanson MA, Beedle AS: Non-genomic transgenerational inheritance of disease risk. BioEssays 2007, 29:। $145-154$.

13. Kriete A, Eils R: Computational Systems Biology London: Elsevier Academic Press; 2006.

14. Holden AV, Pan L, Blanks AM, Evans CJ, Kharche S, Simpson NAB, Smye S, Snowden S, Taggart MJ, Walker JJ, Zhang H: Towards an electrophysiological functional atlas of the uterus in premature and full term labour. Proceedings of the MICCAI Workshop From Statistical Atlases to Personalized Models: Understanding Complex Diseases in Populations and Individuals .

15. Maner WL, Mackay LB, Saade GR, Garfield RE: Characterization of abdominally acquired uterine electrical signals in humans, using a non-linear analytic method. Med Biol Eng Comput 2006, 44:1 $17-123$

16. Devedeux D, Marque C, Mansour S, Germain G, Duchene J: Uterine electromyography: a critical review. Am J Obstet Gynecol 1993, 169:1636-1653.

17. Oczeretko E, Swiatecka J, Kitlas A, Laudanski T, Pierzynski P: Visualization of synchronization of the uterine contraction signals: 
Running cross-correlation and wavelet running cross-correlation methods. 2006, 28:75-8I.

18. Boyett MR, Li J, Inada S, Dobrzynski H, Schneider JR, Holden AV, Zhanh HL: Imaging the heart: computer 3-dimensional anatomic models of the heart. J Electrocardiol 2005, 38: I I3-120.

19. Eils J, Lawerenz C, Astrahantseff K, Ginkel M, Eils R: Databases for systems biology. In Computational Systems Biology Edited by: Kriete A, Eils R. London: Elsevier Academic Press; 2006: 15-38.

20. Yoshino M, Wang SY, Kao CY: Sodium and calcium inward currents in freshly dissociated smooth myocytes of rat uterus. J Gen Physiol 1997, I I 0:565-577.

21. Mankouri HW, Burdyga T, Taggart MJ, Wray S: Simultaneous measurements of electrical activity, intracellular calcium and contraction in smooth muscle. J Physiol 1998, 509.P:2P-3P.

Publish with Bio Med Central and every scientist can read your work free of charge

"BioMed Central will be the most significant development for disseminating the results of biomedical research in our lifetime. "

Sir Paul Nurse, Cancer Research UK

Your research papers will be:

- available free of charge to the entire biomedical community

- peer reviewed and published immediately upon acceptance

- cited in PubMed and archived on PubMed Central

- yours - you keep the copyright

Submit your manuscript here:

http://www.biomedcentral.com/info/publishing_adv.asp 